\title{
Editorial
}

\section{AEPA2018 SPECIAL ISSUE: RECENT ISSUES FOR METAL FORMING RESEARCH}

The 14th Asia-Pacific Symposium on Engineering Plasticity and Its Applications (AEPA) was held at the KAL Hotel Seogwipo during 2-7 December 2018, Jeju Island, Republic of Korea. This conference series has been established as an international forum to present state of the art for modern engineering plasticity and, thus, to provide vision and strategy for further development of the plasticity modeling and experiment.

The present conference was organized by KAIST with the support of KSTP (Korean Society of Technology of Plasticity). It consisted of about 180 presentations conducted in four parallel sessions over a period of four days. Also, educational workshop series were offered for the four selected areas : Constitutive Modeling (F. Barlat), Kinematic Hardening (F. Yoshida and T. Uemori), Forming Limit (T. B. Stoughton), and Polycrystal Modeling (R. Lebensohn) on 2 and 7 December, 2018. Eight special mini-symposia were organized including a honor symposium for Professor Hoon Huh (organized by Soo Sik Han).

AEPA2018 was attended by approximately 200 participants. The conference included scientists, engineers and software developers from academia, research institutions and industry worldwide, and provided a unique forum for stimulating discussions and exchanges of new ideas pertaining to numerical and experimental methods for engineering plasticity. The conference featured five industry plenary lectures, and six academic plenary \& six academic semi-plenary lectures.

This special issue of IJAT includes 10 articles that were selected from the conference which bring to fore current scientific aspects in various field of plasticity and metal forming related to automotive technology. The articles were peer-reviewed in accordance with the editorial policies of the Journal.

ACKNOWLEDGMENTS-The success of this conference, as well as this special issue, depends primarily on all the participants to whom we express our sincere thanks. We also acknowledge the contributions of the conference Co-chairmen, Professors Beom Soo Kang, Young Suk Kim, Heung Nam Han, and also General secretary, Shihoon Choi who made this conference possible, together with the financial support of the AEPA2018 sponsors including POSCO (Platinum), Autoform (Platinum), LG Electronics (Platinum), KIMS (Gold Sponsor), and AFDEX (Silver Sponsor).

Guest Editors

Prof. Jeong Whan Yoon (KAIST, Korea)

Dr. Daeyong Kim (KIMS, Korea)

Publisher's Note Springer Nature remains neutral with regard to jurisdictional claims in published maps and institutional affiliations. 